\title{
Influence of Yttrium Dopant on the Structure and Electrical Conductivity of Potassium Sodium Niobate Thin Films
}

\author{
Maziati Akmal Mohd Hatta ${ }^{a, b *}$, Mohd Warikh Abd Rashid ${ }^{a, d}$, Umar Al-Amani Haji Azlan ${ }^{c}$, Nurul \\ Azuwa Azmi ${ }^{a}$, Mohd Asyadi Azama ${ }^{a}$ Toshihiro Moriga ${ }^{d}$ \\ ${ }^{a}$ Fakulti Kejuruteraan Pembuatan, Universiti Teknikal Malaysia Melaka-UTeM, Hang Tuah Jaya, \\ 76100 Durian Tunggal, Melaka, Malaysia \\ ${ }^{b}$ Faculty of Engineering, International Islamic University Malaysia - IIUM, Jalan Gombak, 53100, \\ Kuala Lumpur, Malaysia \\ ${ }^{c}$ Fakulti Teknologi Kejuruteraan, Universiti Teknikal Malaysia Melaka-UTeM, Hang Tuah Jaya, 76100 \\ Durian Tunggal, Melaka, Malaysia \\ ${ }^{d}$ University of Tokushima and Technical University of Malaysia Melaka Academic Center, The \\ University of Tokushima, Tokushima, Japan
}

Received: January 29, 2016; Revised: August 3, 2016; Accepted: September 29, 2016

\begin{abstract}
KNN thin films with diverse yttrium concentration $(\mathrm{mol} \%=0,0.1,0.3,0.5,0.7$ and 0.9$)$ were fabricated using sol-gel spin coating technique. Doped $\mathrm{KNN}$ revealed that $\mathrm{Y}^{3+}$ was successfully doped into the $\mathrm{ABO}_{3}$ perovskite lattice without changing the phase formation of $\mathrm{KNN}$. The thickness of the deposited layer of KNN produced with increasing dopant concentration was determined to be $200 \mathrm{~nm}$ with dense and well-defined grains. Afterwards, the vibrational bonding and conductivity of KNN films with diverse yttrium concentration were identified according to the charge compensation mechanism. At high dopant concentration of $>0.5 \mathrm{~mol} \%$, O-Nb-O bonding was asymmetric and became distorted due to B-site occupancy by yttrium dopant. Further investigation revealed that charge compensation mechanism was shifted by increasing doping concentration. As a result, yttrium-doped KNN became semi-conductive at low yttrium concentration. Meanwhile, at high concentration, yttrium-doped KNN became an insulator and underwent ionic compensation.
\end{abstract}

Keywords: KNN, yttrium, thin film, doped, structural, conductivity

\section{Introduction}

A significant worldwide attention has been placed on the development and generation of novel types of piezoelectric materials such as sensors, actuators, transducers, filters and resonators. Lead zirconia titanate or PZT has been widely used due to its excellent ferroelectric and piezoelectric properties. However, PZT is believed to cause greenhouse effect due to the presence of toxic lead ${ }^{1,2}$. In order to circumvent this drawback, extensive research is carried out with the focus on the quest for alternative piezoelectric materials. In that respect, potassium sodium niobate $\left(\mathrm{K}_{0.5} \mathrm{Na}_{0.5} \mathrm{NbO}_{3}\right.$ or $\left.\mathrm{KNN}\right)$ has been considered as one of the ceramic materials for new lead-free piezoelectric. It exhibits high Curie temperature $\left(420^{\circ} \mathrm{C}\right)$, high dielectric constant $(\sim 700)$, high remanent polarization $\left(14 \mu \mathrm{C} / \mathrm{cm}^{2}\right)$, low coercive field $(\sim 140 \mathrm{kV} / \mathrm{cm})$ and high piezoelectric constant $(\sim 300 \mathrm{pC} / \mathrm{N})^{3-5}$. However, the fact that $\mathrm{KNN}$ is comprised of $\mathrm{ABO}_{3}$, a perovskite structure that was discovered in the 1950s was ignored through the years due to the difficulties encountered with KNN processing. High volatilization of alkaline elements leads

*e-mail: maziatiakmal@iium.edu.my to compositional in-homogeneity and results in a ceramic with low piezoelectric activity.

The doping technique is believed to be an effective way to compensate the volatility issue of KNN. This can be achieved by doping A-site ions, $(\mathrm{K}, \mathrm{Na})^{+}$or $\mathrm{B}$-site ion, $\mathrm{Nb}^{5+}$. Through this approach, KNN-based materials acquire chemical stability by equilibrating the charge of the ions, which reduce local stress and reduce the concentration of oxygen vacancies ${ }^{6}$. Thus, a study on different types of dopants to generate dense $\mathrm{KNN}$ and good electrical properties is extremely favorable.

Rare-earth dopants are known to demonstrate useful functions of stabilizing and lowering the dissipation factor in dielectric materials due to its low diffusivity characteristics? Yttrium $\left(\mathrm{Y}^{3+}\right)$, which is a type of rare-earth material, is known to be one of the promising dopants. This is because it enhances fatigue endurance, remanent polarization and leakage current ${ }^{8}$. Notably, the ionic radius of $\mathrm{Y}^{3+}$ is $0.91 \AA$, which is between the radii of $\mathrm{K}^{+}, \mathrm{Na}^{+}(1.02 \AA$ and $1.38 \AA)$ and $\mathrm{Nb}^{5+}(0.69 \AA)$. Thus, $\mathrm{Y}^{3+}$ ion can be called as amphoteric ion as $r\left(\mathrm{Nb}^{5+}\right) \leq r\left(\mathrm{Y}^{3+}\right) \leq r\left(\mathrm{~K}^{+}, \mathrm{Na}^{+}\right)$, which can occupy either A-site or B-site of KNN lattice. Besides, it can also act as a donor or acceptor ion. Another important consequence of 
the yttrium doping is the change in the electric conductivity of KNN with regard to its doping site.

Noting that little effort has been made towards understanding the effect of yttrium at KNN lattice, this paper attempts to provide a more complete understanding of the interrelationship between the compositions, microstructures and conductivity of KNN films. Therefore, pure and doped KNN films were prepared using sol-gel spin coating technique. In addition, the effects of yttrium doping on the properties of KNN films are also discussed.

\section{Experiment}

\subsection{KNN films preparation}

KNN solution for KNN thin films was synthesized using sol-gel spin coating technique (Figure 1). Two alkaline precursors, namely potassium acetate (Alfa Aesar, 99\%) and sodium acetate (Alfa Aesar, 99\%) were used as starting solution. The mol $\%$ of the starting precursors was determined to be $50 \mathrm{~mol} \%$ according to the calculated stoichiometry. To compensate the loss of alkaline element, different contents of yttrium $(\mathrm{mol} \%=0,0.1,0.3,0.5,0.7$ and 0.9$)$ were added to the precursors solution.

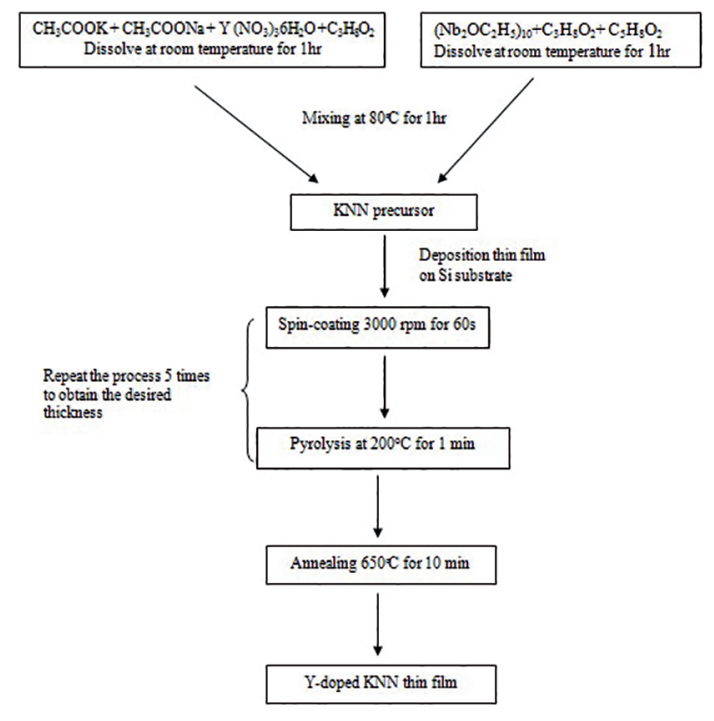

Figure 1: The schematic illustration fabrication of KNN thin film by chemical solution deposition technique.

A mixed solution was dissolved in a polar organic solvent, 2-methyoxyethanol (Sigma Aldrich, 99.9\%) with constant stirring at room temperature. After stirring vigorously for 1 hour at room temperature, the mixed solution of niobium ethoxide and acetyalcetone was added dropwise to the prepared KNN precursors' solution. The resultant solution was kept standing at $80^{\circ} \mathrm{C}$ for 1 hour.
Subsequently, the mixed solution was spun onto the $\mathrm{Si}$ substrate at $3000 \mathrm{rpm}$ for 60 seconds to produce the thin films. After spinning, the wet films were pyrolyzed at $200^{\circ} \mathrm{C}$ for 5 minutes. Next, the thin films were annealed for 5 minutes at $650{ }^{\circ} \mathrm{C}$ in the rapid thermal annealing furnace (RTP-1000D4, MTI.). The thickness of the film was set at approximately $200 \mathrm{~nm}$ by repeating the coating or heat treatment cycle 5 times. Following that, Au films were deposited with the magnetron sputtering at the top and bottom layer of the KNN films for conductivity measurement.

The phase evolution of the KNN and Y-doped KNN films were examined by X-ray diffraction (XRD) using PANalytical X'Pert Pro with a scanning speed of $0.05 \%$. The grain morphology and the cross-section of the grown thin film were examined by Field emission scanning electron microscopy (FESEM), (Hitachi 51400) with an electric potential of 10 $\mathrm{kV}$. Additionally, EDX analyses were carried out to study the composition of the KNN system. The Phonon vibration properties of the KNN molecules with different yttrium compositions were measured by using Raman scattering spectrometer (UniRAM 3500) with a wavelength of 532 $\mathrm{nm}$. The conductivity of these films was measured at room temperature with a testing frequency of $10 \mathrm{kHz}$ by using Precision LCR Meter (U1733P, Agilent).

\section{Results and Discussions}

\subsection{Phase determination of pure and doped KNN}

The crystallinity and phase evaluation of the KNN films are shown in Figure 2. The results were found to be in accordance with the standard orthorhombic KNN pattern (JCPDS, \# 32-0822 and JCPDS\# 33-1270). Generally, both films depicted five prominent peaks with a single KNN phase. However, the pure KNN film revealed the presence of a small peak at $47^{\circ}(2 \theta)$. This peak is known as a secondary phase of $\mathrm{K}_{2} \mathrm{Nb}_{6} \mathrm{O}_{16}$ which is consistent with previous report ${ }^{9}$. The existence of this secondary phase is believed to be due to the high volatilization of the alkaline elements $(\mathrm{K}, \mathrm{Na})^{11,12}$. Furthermore, doped KNN revealed that $\mathrm{Y}^{3+}$ seemed to be successfully doped into the perovskite lattice due to the indestructible $\mathrm{KNN}$ phase. Additionally, incorporation of $\mathrm{Y}^{3+}$ into the $\mathrm{KNN}$ lattice ensured better crystal quality of KNN due to the occupancy of $\mathrm{Y}^{3+}$ at the cation vacancies that diminished the secondary phase.

\subsection{Morphology of the KNN films}

The cross-section of the KNN thin film deposited on $\mathrm{Si}$ substrate is shown in Figure 3. The thickness of the 5-layered KNN thin film determined from the cross-section was approximately $200 \mathrm{~nm}$. Note that the increase in thickness up to $200 \mathrm{~nm}$ was due to thorough crystallization of KNN film at 5-layered deposition. The surface morphologies of 


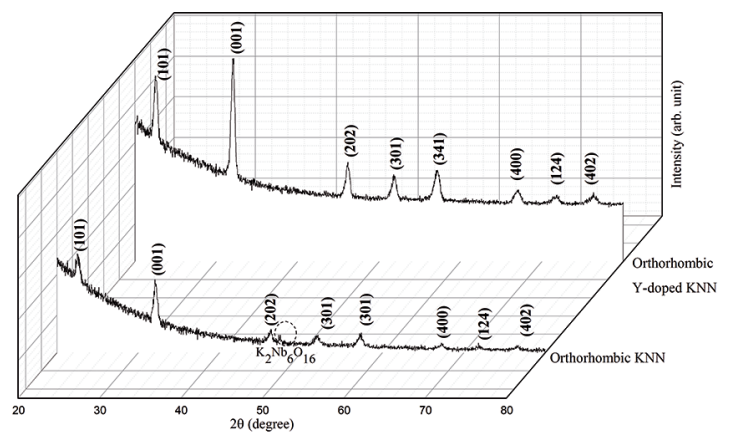

Figure 2: The XRD patterns of pure and Y-doped $\mathrm{KNN}$ in the range of $20^{\circ}$ to $60^{\circ}$. The secondary phase appears at $47^{\circ}$ of pure KNN.

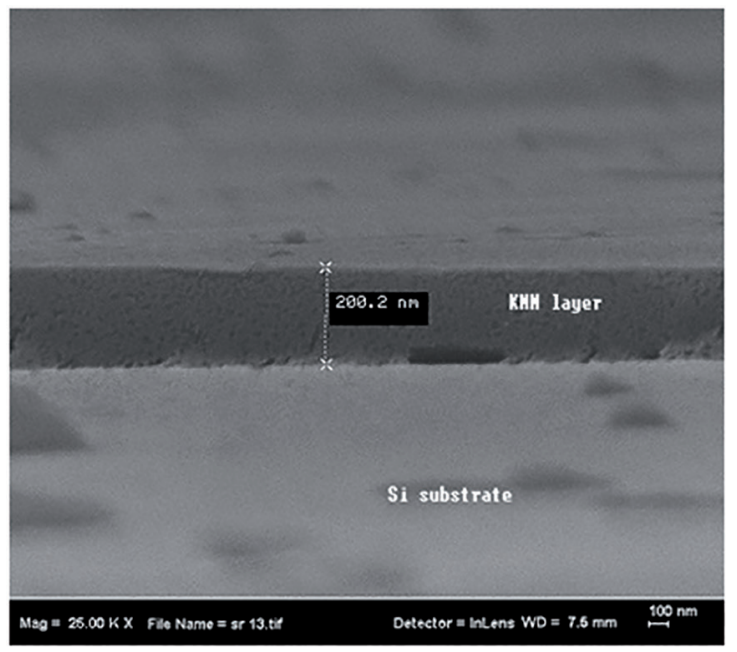

Figure 3: Cross-section FESEM micrographs of 5-layered KNN thin film.

the thin films are depicted in Figure 4. It can be seen that the morphologies of pure and doped $\mathrm{KNN}$ consisted of equiaxed grains (Figure 4(a) - 4(c)). The formation of inhomogeneous morphology and open boundary suggest that the evaporation of alkaline element occurred in pure KNN. This indicates that the Si substrate was exposed in the open grain boundary. This observation was supported by the elemental analysis which confirmed the appearance of Si on the exposed surface of KNN film as depicted in Figure 4a.

However, the grains formation appeared to be dense and more homogenous after the incorporation of yttrium at $0.1 \% \mathrm{~mol}$ (Figure $4 \mathrm{~b}$ ). The microstructure became denser at yttrium $=0.5 \% \mathrm{~mol}$ and the compact boundary was found with no secondary element present. In addition, the EDX analysis performed on the surface of doped film confirmed the presence of the important constituent elements which are $\mathrm{K}$, $\mathrm{Na}, \mathrm{Y}, \mathrm{Nb}$ and $\mathrm{O}$. This structural evolution suggests that $\mathrm{Y}^{3+}$ readily entered the crystal lattice. Notably, previous studies confirmed that the addition of yttrium promotes fine-grained films with high density, presumably due to decreased alkaline volatility upon dopant incorporation ${ }^{7,13-14}$. When a trivalent dopant such as $\mathrm{Y}^{3+}$ is introduced in the $\mathrm{KNN}$ lattice, $\mathrm{K}^{+}$and $\mathrm{Na}^{+}$ions in the KNN lattice would generate defect dipoles with the dopant ion to compensate the electron deficiency. As a result, the KNN structure is positioned statically in the KNN lattice, hence reducing alkaline elements instability ${ }^{15}$. Subsequently, this phenomenon would assist the grains structure to form in a homogenous manner on the KNN surface.

Table 1 shows the EDX spectrum analysis of pure and doped KNN films. According to Table 1, the ratio of K/ $\mathrm{Na}$ that deviated from the stoichiometry may be caused by the volatility of the alkaline elements. Nevertheless, the quantitative results of doped -KNN film showed that the K/ $\mathrm{Na}$ ratio is nearly consistent with the initial stoichiometry suggesting that yttrium is capable of reducing the alkaline elements loss in the KNN formulation.

\subsection{Vibration mode of $K N N$ molecules}

The Raman scattering modes of the KNN molecules with different yttrium compositions are depicted in Figure 5a. The typical vibration confirmed the presence of KNN perovskite structure ${ }^{16-19}$. In all samples, a high Raman intensity around $520 \mathrm{~cm}^{-1}$ were observed due to the typical signal of Si substrate. Additionally, the results depicted the presence of three dominant peaks. $A_{1}$ (LO) and $A_{1}$ (TO) modes evolved around $300 \mathrm{~cm}^{-1}, 619 \mathrm{~cm}^{-1}$ and $860 \mathrm{~cm}^{-1}$. These peaks are attributed to the internal vibration of the $\mathrm{NbO}_{6}$ octahedron, namely the $\mathrm{O}-\mathrm{Nb}-\mathrm{O}$ bending vibration $\left(300 \mathrm{~cm}^{-1}\right)$ and $\mathrm{O}-\mathrm{Nb}-\mathrm{O}$ stretching vibration $\left(619 \mathrm{~cm}^{-1}\right.$ and $\left.860 \mathrm{~cm}^{-1}\right)^{17}$. Some spectral features of the Raman spectrum of doped KNN changed markedly when the concentration of yttrium was increased.

The effects of yttrium dopant on the vibration mode of KNN molecules were explained by analyzing the Raman shifts as well as full-width half maximum (FWHM). Hence, the symmetrical mode at $619 \mathrm{~cm}^{-1}$ was deconvulated using the individual Lorentzian function as shown in Figure 6a. It was observed that the FWHM was decreased for yttrium in the range of $0.1-0.5 \mathrm{~mol} \%$ (Figure $6 \mathrm{~b}$ ). This is attributed to the better crystallinity of the doped KNN structure. Moreover, small Raman shift from 0.1-0.5 mol \% revealed that $\mathrm{Y}^{3+}$ preferentially occupies the A-site of KNN lattice due to less octahedron distortion induced by $\mathrm{Y}^{3+} 20$. The phenomenon can be explained by the close ionic radii of $\mathrm{Y}^{3+}$ and $\mathrm{K}^{+} / \mathrm{Na}^{+}$. Therefore, yttrium doping does not change the force constant for this symmetric stretching mode. However, a dramatic change was observed with increased yttrium doping of more than $0.5 \mathrm{~mol} \%$, accompanied by large changes in Raman scattering intensity and FWHM. This may be attributed to the $\mathrm{O}-\mathrm{Nb}-\mathrm{O}$ angles distortion as a result of $\mathrm{Y}^{3+}$ substitution into $\mathrm{Nb}^{5+}$ or B-site. It is important to know that the $\mathrm{Nb}$-site located at the centre of an oxygen octahedron is a highly symmetrical point. Hence, it is evidenced that the large 

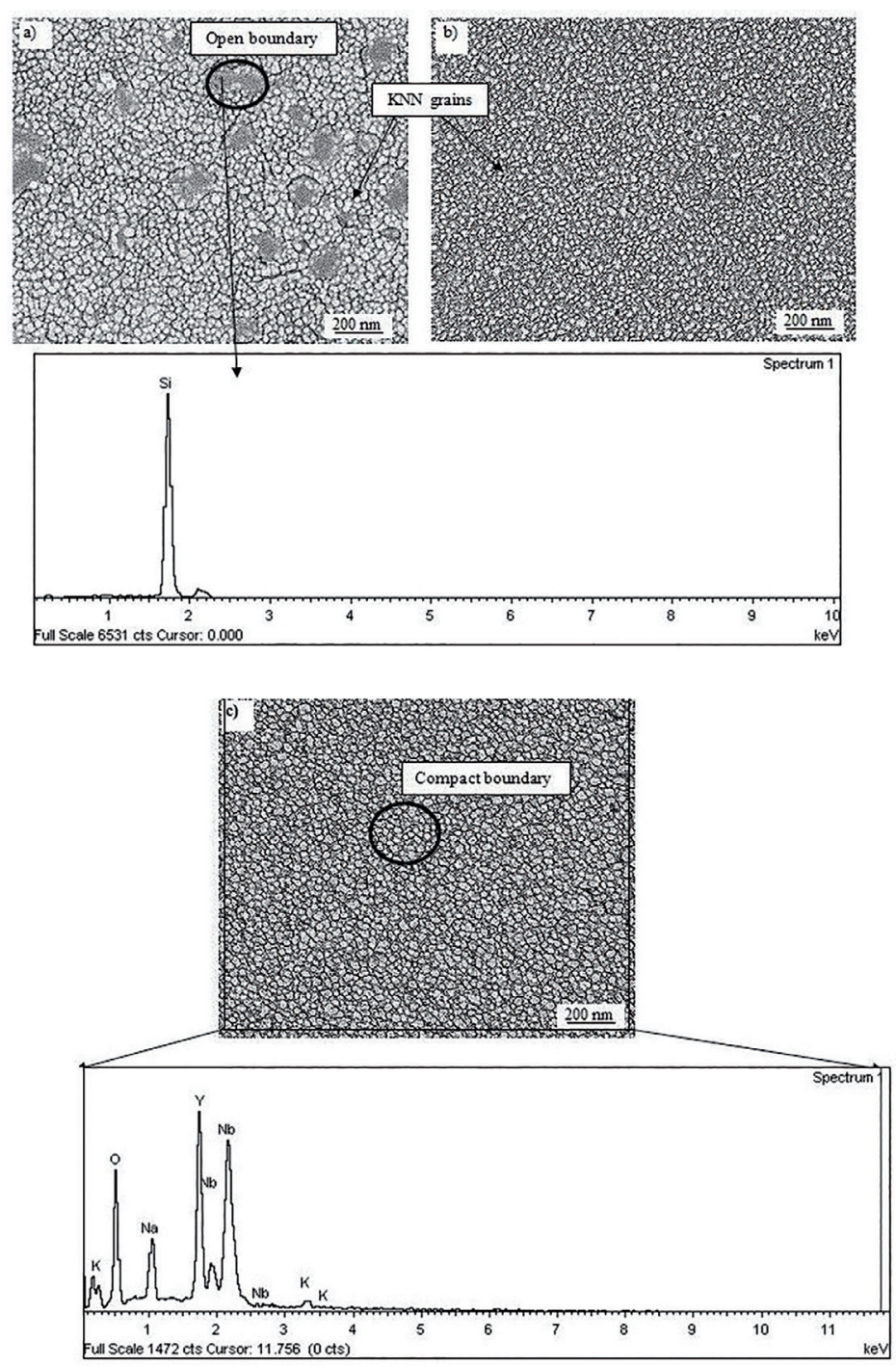

Figure 4: FESEM micrographs of $\mathrm{K}_{0.5} \mathrm{Na}_{0.5} \mathrm{NbO}_{3}$ at different doping contents (mol \%) with corresponding energy dispersive $\mathrm{x}$-ray analysis a) 0 ; b) 0.1 ; c) 0.5 .

Table 1: Quantitative analysis of $\mathrm{KNN}$ films composition in $\mathrm{wt} \%$

\begin{tabular}{lcccccc}
\hline Element & $\mathrm{O} \mathrm{K}$ & $\mathrm{K} \mathrm{K}$ & $\mathrm{Na} \mathrm{K}$ & $\mathrm{Y} \mathrm{L}$ & $\mathrm{Nb} \mathrm{L}$ & $\mathrm{K} / \mathrm{Na}$ \\
\hline Pure KNN & 68.82 & 3.52 & 6.19 & - & 21.47 & 0.56 \\
yttrium-doped KNN films & 49.70 & 6.11 & 5.46 & 7.83 & 30.90 & 1.12 \\
\hline
\end{tabular}

changes in Raman spectra is caused by $\mathrm{Y}^{3+}$ occupation which interrupts the structural disorder of $\mathrm{Nb}-\mathrm{O}$ bonding.

\subsection{Electrical conductivity}

The electrical conductivity of pure and doped $\mathrm{KNN}$ is shown in Figure 7. The effect of yttrium dopant on electrical conductivity is strongly dependent on the yttrium doping site in the perovskite structure ${ }^{21,22}$. In comparison to pure $\mathrm{KNN}$, the conductivity of yttrium-doped KNN increased by the increase of yttrium concentration. The conductivity behavior of the yttrium-doped KNN at low dopant concentration (0.1-0.3 mol \%) indicates that $\mathrm{Y}^{3+}$ is electronically compensated in order to maintain charge neutrality. Moreover, free electrons are produced with the replacement of cation vacancies by yttrium trivalent ion. Hence, at this concentration, the conductivity of $\mathrm{KNN}$ is increased ${ }^{23}$. The associated charge compensation equation is shown below;

$$
\begin{aligned}
& \mathrm{x} Y^{3+}+\left(K^{+} / N a^{+}\right) N b O_{3} \rightarrow \\
& \left.\left[\left(K^{+} / N a^{+}\right)_{1-\mathrm{x}} Y_{\mathrm{x}}^{3+}\right)\right] \\
& {\left[N b_{1-\mathrm{x}}^{5+}\left(N b^{5+} \cdot 2 e\right)_{\mathrm{x}}\right] O_{3}} \\
& +\mathrm{x}\left(\mathrm{K}^{+} / N a^{+}\right)
\end{aligned}
$$




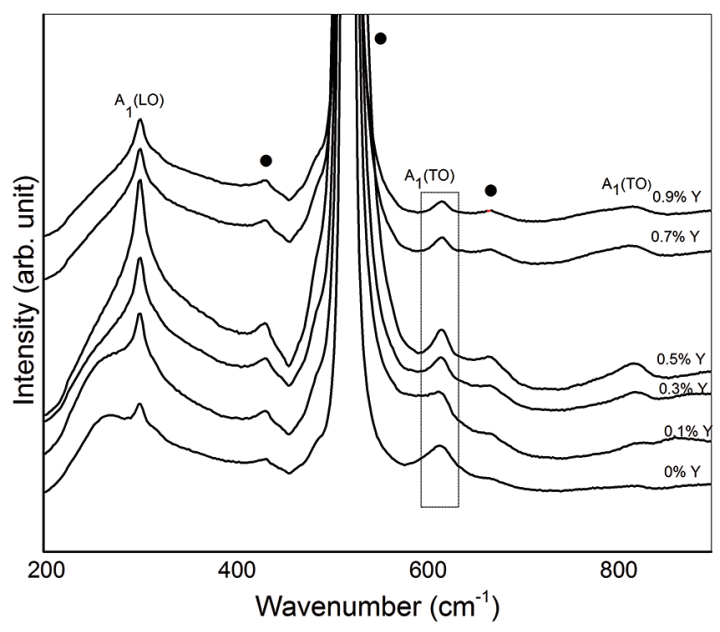

Figure 5: Raman spectra of synthesized $\mathrm{K}_{0.5} \mathrm{Na}_{0.5} \mathrm{NbO}_{3}$ with various dopant compositions.
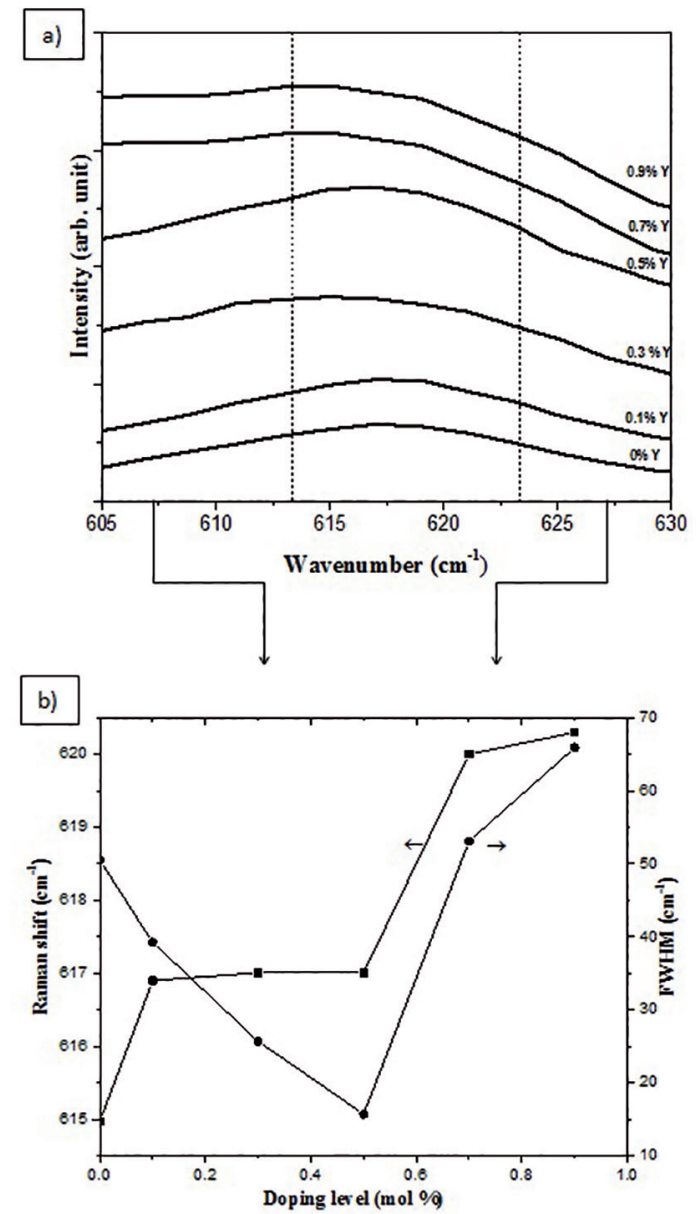

Figure 6: a) The symmetrical mode of Raman spectra mode at 619 $\mathrm{cm}^{-1}$; b) Raman shift and FWHM of yttrium-doped KNN.

On the contrary, yttrium-doped KNN can revert to behave as an insulator when the donor content exceeds the critical

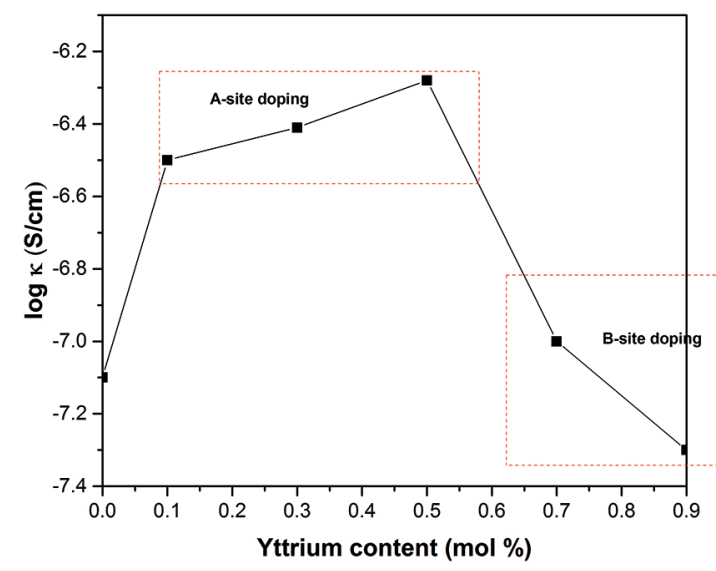

Figure 7: The conductivity of Y-doped KNN films for various mol \%.

concentration. In the present study, the critical concentration determined was $>0.5 \mathrm{~mol} \%$. The mechanism above this composition shifted from the electronic compensation to the ionic compensation as shown in Eq. 2. According to this equation, further incorporation of yttrium would cause this dopant to occupy the B-site or Nb-site of the KNN structure. This incorporation would create ionic compensation between $\mathrm{Nb}^{5+}$ and $\mathrm{Y}^{3+}$ at the $\mathrm{B}$-site and reduce the interaction of octahedron molecules $\left(\mathrm{Nb}^{5+}\right.$ and $\left.\mathrm{O}^{2-}\right)$ as a result. Due to weak octahedron interaction, the oxygen rapidly vaporizes and induces the oxygen vacancies in the KNN lattice ${ }^{24}$. Following that, the oxygen vacancies promote the localized defects in KNN lattices which cause the conductivity to be reduced remarkably.

$$
\begin{aligned}
& \mathrm{x} Y^{3+}+\left(K^{+} / N a^{+}\right) N b O_{3} \rightarrow \\
& \left(K^{+} / N a^{+}\right)_{1-\mathrm{x} / 2}\left(N b_{1-\mathrm{x} / 2}^{5+} Y_{\mathrm{x}}^{3+}\right) O_{3}+ \\
& \mathrm{x}\left(K^{+} / N a^{+}\right)+\mathrm{x} N b^{5+}
\end{aligned}
$$

\section{Conclusion}

In this paper, pure and doped $\mathrm{K}_{0.5} \mathrm{Na}_{0.5} \mathrm{NbO}_{3}$ films (Y-doped $\mathrm{KNN}=0,0.1,0.3,0.5,0.7$ and 0.9 ) were fabricated using sol-gel spin coating technique. Pure KNN film demonstrated the existence of a secondary phase. After yttrium doping, the yttrium incorporated well into KNN lattice by eradicating the secondary phase. The morphologies of the thin films with the thickness of $\sim 200 \mathrm{~nm}$ revealed the homogenous and dense grain after being doped by yttrium. Less distortion on $\mathrm{O}-\mathrm{Nb}-\mathrm{O}$ bonding at low dopant concentration demonstrated that yttrium was incorporated into the A-site lattice. Meanwhile, broad FWHM and significant Raman shifting for yttrium $>0.5 \mathrm{~mol} \%$ were attributed to the structural disorder of octahedron, which implied the incorporation of yttrium into the B-site. The composition and conductivity dependency showed that mol \% of dopant was responsible to determine yttrium lattice site occupancy that governed the conductivity of KNN. Generally, it is suggested that at low yttrium mol $\%, \mathrm{Y}^{3+}$ is electronically compensated. Hence, yttrium-doped 
KNN became semi-conductive at $<0.5 \mathrm{~mol} \%$ of yttrium. Further incorporation of yttrium indicated that doped KNN underwent ionic compensation by occupying the B-site of $\mathrm{KNN}$ structure. As a result, yttrium-doped KNN became an insulator due to the presence of oxygen vacancies.

\section{Acknowledgements}

The authors would like to thank the Ministry of Higher Education, Malaysia for funding our research (FRGS/1/2014/ TK04/UTEM/02/3).

\section{References}

1. Matsubara M, Yamaguchi T, Kikuta K, Hirano S. Sinterability and Piezoelectric Properties of $(\mathrm{K}, \mathrm{Na}) \mathrm{NbO}_{3}$ Ceramics with Novel Sintering Aid. Japanese Journal of Applied Physics. 2004;43(10):7159-7163.

2. Rani R, Sharma S. Influence of Sintering Temperature on Densification, Structure and Microstructure of $\mathrm{Li}$ and $\mathrm{Sb} \mathrm{Co}-$ Modified (K,Na) $\mathrm{NbO}_{3}$-Based Ceramics. Materials Sciences and Applications. 2011;2(10):1416-1420.

3. Ringgaard E, Wurlitzer T. Lead-free piezoceramics based on alkali niobates. Journal of the European Ceramic Society. 2005;25(12):2701-2706.

4. Mgbemere HE, Herber RP, Schneider GA. Investigation of the dielectric and piezoelectric properties of potassium sodium niobate ceramics close to the phase boundary at $\left(\mathrm{K}_{0.35} \mathrm{Na}_{0.65}\right) \mathrm{NbO}_{3}$ and partial substitutions with lithium and antimony. Journal of the European Ceramic Society. 2009;29(15):3273-3278.

5. Matsubara M, Yamaguchi T, Kikuta K, Hirano S. Effect of Li Substitution on the Piezoelectric Properties of Potassium Sodium Niobate Ceramics. Japanese Journal of Applied Physics. 2005;44(8):6136-6142.

6. Qian S, Zhu K, Pang X, Liu J, Qiu J, Du J. Phase transition, microstructure, and dielectric properties of $\mathrm{Li} / \mathrm{Ta} / \mathrm{Sb}$ co-doped $(\mathrm{K}, \mathrm{Na}) \mathrm{NbO}_{3}$ lead-free ceramics. Ceramics International. 2014;40(3):4389-4394.

7. Kim JH, Kang YM, Byun MS, Hwang KT. Study on the chemical stability of Y-doped $\mathrm{BaCeO}_{3-} \delta$ and $\mathrm{BaZrO}_{3-} \delta$ films deposited by aerosol deposition. Thin Solid Films. 2011;520(3):1015-1021.

8. Li C, Liu M, Zeng Y, Yu D. Preparation and properties of yttrium-modified lead zirconate titanate ferroelectric thin films. Sensors and Actuators A: Physical. 1997;58(3):245-247.

9. Maziati AMH, Mohd WAR, Al-Amani AU. Physical and electrical properties enhancement of rare-earth doped-potassium sodium niobate: a review. Ceramics-Silikaty. 2015;59(2):158-163.

10. Bathelt R, Soller T, Benkert K, Schuh C, Roosen A. Neodymium doping of KNNLT. Journal of the European Ceramic Society. 2012;32(14):3767-3772.
11. Mahesh P, Pamu D. Effect of deposition temperature on structural, mechanical, optical and dielectric properties of radio frequency sputtered nanocrystalline $\left(\mathrm{K}_{x} \mathrm{Na}_{1}-x\right) \mathrm{NbO}_{3}$ thin films. Thin Solid Films. 2014;562:471-477.

12. Zhu M, Shang X, Chang G, Li M, Liu X, Zhou T, et al. Pulsed laser deposition of single-phase lead-free NKLNST thin films with K- and Na-excess targets. Journal of Alloys and Compounds. 2013;567:97-101.

13. Zhou J, Ma Q, Wang P, Cheng L, Liu S. Influence of rare-earth $\mathrm{Nd}$, Dy, and Ho doping on structural and electrical properties of $\left(\mathrm{Na}_{0.53} \mathrm{~K}_{0^{*} 47}\right)_{0.942} \mathrm{Li}_{0 \cdot 058} \mathrm{NbO}_{3}$ based lead-free piezoceramics. Ceramics International. 2014;40(1Part B):2451-2459.

14. Kishi H, Kohzu N, Sugino J, Ohsato H, Iguchi Y, Okuda T. The effect of rare-earth (La, Sm, Dy, Ho and Er) and $\mathrm{Mg}$ on the microstructure in $\mathrm{BaTiO}_{3}$. Journal of the European Ceramic Society. 1999;19(6-7):1043-1046.

15. Li JF, Zhen Y, Zhang BP, Zhang LM,Wang K. Normal sintering of $(\mathrm{K}, \mathrm{Na}) \mathrm{NbO}_{3}$-based lead-free piezoelectric ceramics. Ceramics International. 2008;34(4):783-786.

16. Nakashima Y, Sakamoto W, Yogo T. Processing of highly oriented $(\mathrm{K}, \mathrm{Na}) \mathrm{NbO}_{3}$ thin films using a tailored metal-alkoxide precursor solution. Journal of the European Ceramic Society. 2011;31(14):2497-2503.

17. Vendrell X, García JE, Bril X, Ochoa DA, Mestres L, Dezanneau G. Improving the functional properties of $\left(\mathrm{K}_{0.5} \mathrm{Na}_{0 .}\right)_{5} \mathrm{NbO}_{3}$ piezoceramics by acceptor doping. Journal of the European Ceramic Society. 2015;35(1):125-130.

18. Wang Z, Zhuo Y, Xiao D, Wu W, Zhang C, Huang X, et al. Ferroelectric properties of rare-earth oxides doped $\left(\mathrm{K}_{0.4} \mathrm{Na}_{0.6}\right)_{0 \cdot 9}$ ${ }_{5} \mathrm{Li}_{0.05}\left(\mathrm{Nb}_{0.95} \mathrm{Sb}_{0.05}\right) \mathrm{O}_{3}$ lead-free piezoceramics. Current Applied Physics. 2011;11(3 Suppl):S143-S148.

19. Raghavender M, Kumar GS, Prasad G. Modification of dielectric relaxations in sodium bismuth titanate with samarium doping. Journal of Physics and Chemistry of Solids. 2006;67(8):18031808 .

20. Hushur A, Ko JH, Kojima S, Lee SS, Jang MS. Raman scattering study of A- and B-site substitutions in ferroelectric $\mathrm{Bi}_{4} \mathrm{Ti}_{3} \mathrm{O}_{12}$. Journal of Korean Physical Society. 2002;41(5):763-768.

21. Akmal M, Al-Amani U, Warikh M, Azuwa N. Enhanced structural and electrical properties of lead-free y-doped $(\mathrm{K}, \mathrm{Na}) \mathrm{NbO}_{3}$ thin films. Jurnal Teknologi. 2015;77(21):67-71.

22. Pu Y, Chen W, Chen S, Langhammer H. Microstructure and dielectric properties of dysprosium-doped barium titanate ceramics. Cerâmica. 2005;51(319):214-218.

23. Jha PA, Jha AK. Effects of yttrium substitution on structural and electrical properties of barium zirconate titanate ferroelectric ceramics. Current Applied Physics. 2013;13(7):1413-1419.

24. Yu Q, Li JF, Chen Y, Cheng LQ, Sun W, Zhou Z, et al. Effect of Pyrolysis Temperature on Sol-Gel Synthesis of Lead-free Piezoelectric (K,Na) $\mathrm{NbO}_{3}$ Films on $\mathrm{Nb}: \mathrm{SrTiO}_{3}$ Substrates. Journal of the American Ceramic Society. 2014;97(1):107-113. 